Proceedings

\title{
Some Sociological Issues of the Information-Internet Engineering ${ }^{\dagger}$
}

\author{
Sanhu Li \\ Professor of Guangzhou Academy of Governance, No. 99, Xianlie Middle Road, Guangzhou 510070, China; \\ Sh.li@foxmail.com \\ † Presented at the IS4SI 2017 Summit DIGITALISATION FOR A SUSTAINABLE SOCIETY, Gothenburg, \\ Sweden, 12-16 June 2017.
}

Published: 8 June 2017

\begin{abstract}
In contemporary age, the information-internet engineering has been expanding to a global scale, and its deeply social embeddedness is characterized with the digital/material imbrications, cyberspace/user mediating practices, where a new network society emerges. In the network society, newly regional centers are made in the reconstruction of geographical space, personal growth becomes a cyber-action, and unadorned social structure now turns into the network structure. This new network society is a risk society, giving rise to both the disorganized actions (online mass incidents) and the deviant actions (telecommunication frauds). These actions violate the modest standards of public morality, influences on and even ruins the social life. In the face of so many social problems as well as challenges produced by the information-interwork engineering, it is emphasized that the engineering innovations(developing anti-hacker technologies) should play a panopticon-like role in the social governance of network, with its certain synopticon-like management as self-control (the supervision from the public via network) and legal management as external force.
\end{abstract}

Keywords: information-internet; network society; social problems; social governance

\section{Introduction}

The information-internet engineering has been bringing up a new existence state of human society. To this new existence, all kinds of classical theories of sociology appear beyond its explaining and understanding, and even are completely powerless [1] (p. 100). The challenge of informationinternet engineering for sociology lies in how to construct its relations to the sociological world. This is not to deny the weight of technology, but to develop analytic categories that allow us to capture the complex imbrications of technology and society [2] (p. 365).The article discusses on the social embeddedness of information-internet engineering, investigating the emergence and development of new network society, dividing the social problems of network into the disorganization typed and the deviance typed, and thereby suggesting three paths of governance-the panopticon-like technological, the synopticon-like autonomous and the legal.

\section{The Information-Internet Engineering and Its Social Embeddedness}

The Information-network engineering has been advancing from stand-alone computer to the social level of computer interconnecting with mobile phone. This development is both an engineering process and a social process. The technological paradigm of information-internet engineering brings convenience for human life, making human life from the real space into the virtual space. 


\subsection{The Emergence and Characteristics of Information-Internet Engineering}

Information-internet engineering is to make structurally computer nodes connecting together, and develops a global network. Internet consists of communication facilities that control services, including both hardware and software. The Internet hardware facilities are used to support the operation of software systems, the design and standardization of software systems lays foundations for the expansion of internet. Since the development of WWW in the 1990s, web page has evolved from the complete format of servers to the Hypertext Markup Language (HTML) format that can transmit data to browser, and creating and delivering web services become a dynamic, flexible design interaction process.

\subsection{The Social Embeddedness of Information-Internet Engineering}

The social embeddedness firstly manifests as the superposition of the digital technology/material activities. It is important to realize that not only information network space is based on computer and mobile phone manufacturing, and software design, but also networking activities are influenced by offline culture, material practice and image production. The social embeddedness manifests also as the superposition of the digital technology / user mediating practice. It is not a purely technical event, but influenced by values culture, power system and institutional order.

\section{The Rise and Development of New Network Society}

The social embeddedness of information-internet engineering has been bringing about drastic changes of society. Castells argued that new information technology as a material culture is a socially embedded process, not as an exogenous factor affecting society [3] (p. 693).It is to say that the information-internet engineering itself implies the rise and development of new network society.

\subsection{Traditional Geographical Space Remodeled by the Internet}

With the development and widespread applications of the internet, today's cyberspace reorganization has broken the institutional boundaries among countries. This does not mean that old geographical hierarchy is gone, but that geographical hierarchy is reorganized along the original order. For example, cross-regional transactions in global urban networks are shifting from traditional transport and tourism to information cyberspace, constituting new geographies of centrality [2] (p. 375).

\subsection{Personal Growth Stimulated by Individual Networking Actions}

Traditional micro-sociological theory attempts to show that individuals grow through learning and education. However, this growth is now the mutual online learning, and individual roles are partly identified through information network. According to a questionnaire survey of college students in Anhui Province, their social self-evaluation has the greatest influence on the online learning motivation, and the least influential is the online entertainment behavior [4] (pp. 26-27).

\subsection{The Social Structure Reorganized by the Information Network}

Network on internet is "the product of what the information technology has been promoting the innovation, differentiation, integration and extension of technology and related institution, norms and values to satisfy human needs" [5] (p. 77).New network society is a world of social restructuring, which is broadly reflected in social organization and social cluster level and whose networking advantage is that it overcomes traditional social network's bad performing in mobilizing resources and focusing these resources on the execution of a given task [3] (p. 695). 


\section{The Social Problems of Information-Internet Engineering}

New network society "triggers uncertainties and possibilities extremely growing, so that risk has become its internal constituent element" [6] (p. 20). In other words, network society is essentially a risk society, or "risk society of network". We tend to divide the social problems of network into the social disorganization and the social deviance typed.

\subsection{The Disorganization Typed Social Problems of Network Society}

The social embeddedness of information-internet engineering brought about the local disorganized chaos or disorder that has not the overall impacts on the social structure. We call this as the disorganization typed social problems of network, which can be divided into the disorganization of individual and the disorganization of group. In the disorganization of individual, "the network gate event of 1990th borne youth" [7] (pp. 143-149) is the most typical. As with the disorganization of group, the network grouping event is "an event where a number of Internet users for a specific purpose around the hot issues, publish and bring critical opinions largely in the public domain, and then affect the real life" [8] (p. 96).

\subsection{The Deviance Typed Social Problems of Network Society}

We can divide the deviance typed social problems of network into two categories: the destruction of values and the destruction of means. The destruction of values currently focuses on the performance of the network fraud cases that continue to occur. In recent time, two telecommunications frauds with which two college students in Shandong and one professor from Tsinghua University met occurrence due to their information leakage. In the destruction of means, hacker attack is the most serious.

\section{The Multi-Dimensional Pathes to Social Governance of Network}

From the sociological point of view, so-called social governance of network is 'the governance to some social problems based on the relationship among people on the Internet' [9] (p. 30). Focusing on technology, social autonomy and the rule of law, we discuss on the social governance approaches of network.

\subsection{The Panoticon-Like Technological Governance of Network Society}

The metaphors "information panopticon", "digital panopticon" and "online panopticon", express a technological determinism of social governance. However, to the means destruction typed social problems, some technical responses result in the information-internet security engineering industry, such as firewall and its related secret key technology, anti-virus software, anti-hacker software, and even quantum communication, infiltrating in the national defense or military, government, finance, hospitals and families.

\subsection{The Synopticon-Like Autonomous Governance of Network society}

The technological governance would not avoid both the disorganization typed problems and the deviance typed problems with the destruction of values, so sociologists begin to go beyond the concept "panopticon" to find another governance approaches such as online self-control and large data prediction like "synopticon", to say "the many to see and contemplate the few" [10] (p. 219). This is the parallel governance model or the autonomous governance for netizen self to solve the disorganization typed social problems of network.

\subsection{The Legal Governance of Network Society}

China's "Network Security Act" (implemented in 1 June 2017) marks that the development of network society has the basic legal norms in China. It defines "the maintenance of network security" as the social governance capability to protect network from attacks, intrusion, interference, 
destruction, illegal use and contingency, and to ensure the integrity, confidentiality and usability of network data. Firstly, paying equal attention to the network development and the network security, the government maintains the spatial security and order network society. Secondly, for the disorganization typed social problems of network, the government lays emphasizes on guiding, monitoring and early warning and emergency responses. Thirdly, for the deviance typed social problem of network, the government increases efforts to punish.

Conflicts of Interest: The author declares no conflict of interest.

\section{References}

1. Tong, X.; Luo, J. Network Society and Its Challenges to the Theory of Classical Sociology. J. Nanjing Univ. Philos. Humanit. Soc. Sci. 2001, 38, 96-102.

2. Saskia, S. Towards a Sociology of Information Technology. Curr. Soc. 2002, 50, 365-388.

3. Manuel, C. Toward a Sociology of the Network Society. Contemp. Soc. 2000, 29, 693-699.

4. Zhao, H. On the Relationship between the Network Actions and the Social Self-Awareness of College Students. J. Hubei Corresp. Univ. No.4, 2005, 26-27.

5. Feng, P.Z. The Provisions and Characteristics of Network Action: the Starting Point of Network Sociology. Acad. Circ. No.2, 2001, 74-84.

6. Huang, S.H. The Social Problems of Network in the Perspective of Risk Society. Sci. Soc. 2013, 3, 14-22.

7. Li, S.W.; Zhao, Q. Thinking through the "Post 90" Youth Network Gate Event: Based on the Social Disorganization Theory. J. Northwest A F Univ. Soc. Sci. Ed. Vol. 12, No.6, 2012, 143-149.

8. Hao, Q.H. On the Conception of Network Group Event. Qilu J. No.1, 2013, 96-100.

9. Xiong, G.Q. Online Social Governance and National Political Security in China. Soc. Sci. No.12, 2015, 29-33.

10. Thomas, M. The Viewer Society: Michel Foucault's 'Panopticon' Revisited. Theor. Criminol. 1997, 1, $215-234$. 